\title{
The insulin-sensitivity sulphonylurea receptor variant is associated with thyrotoxic paralysis
}

\author{
Ana Luiza R Rolim, Susan C Lindsey, Ilda S Kunii, Felipe Crispim, \\ Regina Célia M S Moisés, Rui M B Maciel and Magnus R Dias-da-Silva
}

Laboratory of Molecular and Translational Endocrinology, Department of Medicine, Escola Paulista de Medicina, Universidade Federal de São Paulo (UNIFESP), Rua Pedro de Toledo, 669, $11^{\circ}$ andar, 04039-032 São Paulo, SP, Brazil

Correspondence should be addressed to M R Dias-da-Silva Email

mrdsilva@unifesp.br

\begin{abstract}
Thyrotoxicosis is the most common cause of the acquired flaccid muscle paralysis in adults called thyrotoxic periodic paralysis (TPP) and is characterised by transient hypokalaemia and hypophosphataemia under high thyroid hormone levels that is frequently precipitated by carbohydrate load. The sulphonylurea receptor 1 (SUR1 $(A B C C 8)$ ) is an essential regulatory subunit of the $\beta$-cell ATP-sensitive $\mathrm{K}^{+}$channel that controls insulin secretion after feeding. Additionally, the SUR1 Ala1369Ser variant appears to be associated with insulin sensitivity. We examined the $A B C C 8$ gene at the single nucleotide level using PCR-restriction fragment length polymorphism (RFLP) analysis to determine its allelic variant frequency and calculated the frequency of the Ala1369Ser C-allele variant in a cohort of 36 Brazilian TPP patients in comparison with 32 controls presenting with thyrotoxicosis without paralysis (TWP). We verified that the frequency of the alanine $1369 \mathrm{C}$-allele was significantly higher in TPP patients than in TWP patients ( 61.1 vs $34.4 \%$, odds ratio $(O R)=3.42, P=0.039$ ) and was significantly more common than the minor allele frequency observed in the general population from the 1000 Genomes database ( 61.1 vs $29.0 \%, O R=4.87, P<0.005$ ). Additionally, the $C$-allele frequency was similar between TWP patients and the general population (34.4 vs $29 \%$, $\mathrm{OR}=1.42, P=0.325)$. We have demonstrated that SUR1 alanine 1369 variant is associated with allelic susceptibility to TPP. We suggest that the hyperinsulinaemia that is observed in TPP may be linked to the ATP-sensitive $\mathrm{K}^{+} / \mathrm{SUR} 1$ alanine variant and, therefore, contribute to the major feedforward precipitating factors in the pathophysiology of TPP.
\end{abstract}

Journal of Molecular Endocrinology (2014) 53, 295-301

\section{Introduction}

Thyrotoxic periodic paralysis (TPP) is an acute manifestation of thyrotoxicosis and is characterised by transient episodes of flaccid muscle paralysis, hypokalaemia and hypophosphataemia that occur only in the presence of high thyroid hormone levels (Dias da Silva et al. 2002, Lin et al. 2003, Lin 2005, Maciel et al. 2011). TPP is the most frequent cause of acquired acute flaccid paralysis in adults (20-40 years of age) and demonstrates a strong

\author{
Key Words \\ - $A B C C 8$ \\ - genetic susceptibility \\ - thyrotoxicosis \\ - periodic paralysis
}


combination of environmental factors, genetics and thyrotoxicosis (Silva et al. 2004, Lin 2005, Maciel et al. 2011). Indeed, attacks of muscle weakness may be triggered by the ingestion of sweet snacks, alcohol consumption, or after vigorous physical exercise (Chang et al. 2013). Recently, a collaborative study identified mutations in a previously unreported gene that was named KCNJ18 in $33 \%$ of unrelated TPP patients (Ryan et al. 2010). This gene encodes an inwardly rectifying potassium (Kir) channel subunit Kir2.6, and is primarily expressed in skeletal muscle and transcriptionally regulated by tri-iodothyronine $\left(\mathrm{T}_{3}\right)$ (Ryan et al. 2010). However, the absence of Kir2.6 mutations in the majority of TPP patients indicates that other susceptibility genes remain yet to be identified.

Both $\mathrm{T}_{3}$ and insulin can activate the $3 \mathrm{Na}^{+} / 2 \mathrm{~K}^{+}$ ATPase pump. Results from several studies have indicated that the activity of the $3 \mathrm{Na}^{+} / 2 \mathrm{~K}^{+}$ATPase pump is increased in thyrotoxicosis and is further exacerbated in patients with TPP (Chan et al. 1991, 1994). Results from clinical studies also indicated that the serum insulin level is elevated before and during the paralysis episodes (Shishiba et al. 1972, Hamada et al. 1985). Chan et al. (1994) demonstrated the role of insulin in the pathogenesis of TPP. These authors showed an increased insulin response in a glucose tolerance test and a higher platelet $3 \mathrm{Na}^{+} / 2 \mathrm{~K}^{+}$ATPase activity in TPP patients compared with healthy control subjects and thyrotoxicosis patients without paralysis (Chan et al. 1994). Recently, we have proposed a feedforward model for TPP pathophysiology (Maciel et al. 2011). According to this model, in a genetically susceptible thyrotoxic patient, the combination of an over-activated $3 \mathrm{Na}^{+} / 2 \mathrm{~K}^{+}$ATPase pump with hyperinsulinaemia and abnormally increased glucose-stimulated insulin secretion result in reduced outward $\mathrm{K}^{+}$efflux in skeletal muscle, which causes hypokalaemia and culminates in the depolarisationinduced acute loss of muscle excitability (Kung 2006, Rolim et al. 2010, Maciel et al. 2011). Among seven hyperinsulinaemia genome loci, the ATP-sensitive potassium (KATP) channel genes ATP-binding cassette transporter sub-family $\mathrm{C}$ member 8 (ABCC8) and KCNJ11 are strong candidates for new TPP susceptibility studies.

Therefore, based on the thyrotoxic distress in muscle and the serum insulin response to a carbohydrate load in TPP subjects, we screened genes related to the metabolic equilibrium of glucose in muscle cells, including KATP channel genes, especially those regulated by $\mathrm{T}_{3}$, which arbitrate the slow-to-fast-twitch muscle fibre change. Therefore, we investigated whether variants of KATP channels (i.e. Kir6.2 and sulphonylurea receptor 1
(SUR1)) that participate in insulin secretion and glucose uptake in muscle could be associated with TPP. In this study, we explore the relationship between the $A B C C 8$ gene variant Ala1369Ser and susceptibility to TPP.

\section{Materials and methods}

\section{Subjects}

We recruited 68 male thyrotoxic patients, of whom 36 presented with TPP and 32 were control subjects presenting with Graves' disease without a history of paralysis (i.e. thyrotoxic without paralysis; TWP). TPP patients have been treated at the Endocrinology Outpatient Service of Sao Paulo Hospital since 1997. Additionally, 1092 genotypes of variant frequencies (SNPs) were obtained from the 1000 Genomes database as a population genetics control (Flicek et al. 2013).

TPP was diagnosed based on clinically significant acute muscle weakness attacks that were accompanied by hypokalaemia and thyrotoxic symptoms. All TPP patients exhibited suppressed levels of TSH, increased levels of thyroid hormone (total and free thyroxine $\left(\mathrm{T}_{4}\right)$ ) and hypokalaemia with serum potassium levels of $<3.5 \mathrm{mmol} / \mathrm{l}$ (normal range: $3.5-5.0 \mathrm{mmol} / \mathrm{l}$ ). Patients with another established aetiology of paralysis or hypokalaemia (e.g. paralysis that was secondary to drugs or renal or intestinal $\mathrm{K}^{+}$wasting) were excluded. Peripheral blood samples were collected after a written informed consent had been obtained from each subject. The protocol was approved by the local research ethics committee (CEP-UNIFESP 0940/11).

\section{Molecular analysis}

Genomic DNA was extracted from peripheral blood leukocytes of TTP and control subjects using the Puregene DNA isolation kit (Gentra Systems, Minneapolis, MN, USA). Spectrophotometric DNA quantification was performed using a NanoDrop 2000 spectrophotometer. We searched for the ABCC 8 gene variant Ala1369Ser (rs757110) using PCR-restriction fragment length polymorphism (PCR-RFLP) screening and subsequent direct sequencing analyses.

The $A B C C 8$ gene region encompassing the Ala1369Ser variant (rs757110) was amplified using the following primers: forward, 5'-GGG AAG AGT CCA AGG AGG AG-3', and reverse, 5'-CAG GAG ACT GCG ATG TCT GA-3'. We amplified the $A B C C 8$ gene using PCR and $200 \mathrm{ng}$ of genomic DNA, $12.5 \mu$ l of Promega PCR Master Mix and

Published by Bioscientifica Ltd. 
$10 \mathrm{pmol}$ of each primer in a total reaction volume of $25 \mu \mathrm{l}$ under the following conditions: initial DNA denaturation at $94{ }^{\circ} \mathrm{C}$ for $5 \mathrm{~min}$ followed by 35 cycles of $30 \mathrm{~s}$ of denaturation at $94{ }^{\circ} \mathrm{C}, 30 \mathrm{~s}$ of annealing at $55^{\circ} \mathrm{C}$ and $45 \mathrm{~s}$ of extension at $72{ }^{\circ} \mathrm{C}$, with 10 -min final extension at $72^{\circ} \mathrm{C}$ to complete the reaction. Each $5-\mu \mathrm{l}$ PCR product was analysed on a 1\% agarose gel and then purified using the illustra GFX PCR DNA and Gel Band Purification Kit (GE Healthcare, Buckinghamshire, UK).

PCR fragments were sequenced using BigDye Terminator v3.1 mix and the identical primers that were used for amplification and were subsequently analysed on an ABI Prism 3130x Capillary Electrophoresis Sequencer (Applied Biosystems). We performed PCR-RFLP analysis using the MwoI restriction enzyme (New England Biolabs, Beverly, MA, USA) and NEBcutter 2.0 (http://tools.neb.com/ NEBcutter2/) (Vincze et al. 2003). Restriction digests were performed in a $20-\mu \mathrm{l}$ reaction mixture containing $10 \mu \mathrm{l}$ of PCR product, $2 \mu \mathrm{l}$ of $10 \times$ NEBuffer $3,0.5 \mu \mathrm{l}$ of MwoI and $7.5 \mu \mathrm{l}$ of sterile deionised water and were incubated at $60{ }^{\circ} \mathrm{C}$ for $1 \mathrm{~h}$. The A-allele variant contains two MwoI restriction sites and is digested to 195-, 106- and 92-bp fragments, whereas the $\mathrm{C}$ allele contains a third MwoI cleavage site and is digested to 195-, 106-, 51- and 41-bp fragments. The resultant DNA fragments were then separated according to size using a 3\% NuSieve GTG agarose gel (FMC BioProducts, Rockland, ME, USA) and were visualised using GelRed (Biotium, Hayward, CA, USA) staining under u.v. light.

\section{Statistical analyses}

The allele and genotype frequencies were compared between TPP patients and TWP controls using the $\chi^{2}$-test or independent Student's $t$-test whenever appropriate. The association between the ABCC 8 Ala1369Ser variant and the risk of TPP was estimated by the odds ratio (OR) and considering the $95 \%$ CIs, using the non-risk genotype $(\mathrm{AC}+\mathrm{AA})$ as a reference. Statistical significance was defined as an $\alpha$ risk $<0.05$, and Hardy-Weinberg equilibrium was evaluated. Statistical analyses were performed using IBM SPSS Statistics version 22.0 (IBM Corp., Armonk, NY, USA) and GraphPad Prism version 3.0 (GraphPad Software, La Jolla, CA, USA).

\section{Results}

We studied 36 TPP patients and 32 sex-matched controls. The anthropometric measurements and clinical and biochemical features of the TPP and TWP subjects are summarised in Table 1. The TWP control group is similar to the TPP group regarding the percentage of mixed Black/Caucasians (41 and 43\%, respectively) and Caucasians (34 and 37\%, respectively), different in the percentage of black patients (25 and 6\%, respectively), whilst Asian (11\%), and Indian (3\%) patients were only present in the TPP group. The mean age of TPP patients was $28.56 \pm 7.73$ years (range: $19-51$ years) and the mean age of TWP patients was $40.77 \pm 11.57$ years (range: $20-66$ years). In TPP patients, the initial serum potassium level measured before treatment was $2.25 \pm 0.55 \mathrm{mmol} / \mathrm{l}$ (range: $1.2-3.4 \mathrm{mmol} / \mathrm{l}$ ), whereas the initial serum potassium level was within the normal range in the TWP control patients $(4.52 \pm 0.39 \mathrm{mmol} / \mathrm{l}$; range: $4.0-5.2 \mathrm{mmol} / \mathrm{l})$. There was no difference in the serum TSH and free $\mathrm{T}_{4}$ levels between the TPP and the TWP control patients.

In contrast to the BMI that was determined at the time of thyrotoxicosis diagnosis, the BMI that was determined at the time of the last follow-up visit while in a euthyroid state was higher in TPP patients than in the TWP controls $\left(30.05 \pm 5.34\right.$ vs $\left.26.93 \pm 2.73 \mathrm{~kg} / \mathrm{m}^{2}, P=0.041\right)$.

The distribution of the Ala1369Ser (rs757110) genotype frequency was examined in TPP patients and TWP subjects; representative electropherogram sequences and restriction analyses are shown in Fig. 1. Genomic DNA obtained from TPP patients $(n=27)$ and population controls $(n=32)$ was genotyped. As shown in Table 2, the frequency of the $\mathrm{C}$ allele was significantly higher in

Table 1 Summary of the clinical features of TPP and TWP patients. Age at diagnosis, potassium levels and anthropometric data are expressed as the median, total number and range when the clinical data were available

\begin{tabular}{l} 
Feature \\
\hline Age (years) \\
Potassium $(3.5-5.0 \mathrm{mmol} / \mathrm{l})$ \\
$\mathrm{TSH}(0.35-5.0 \mathrm{mU} / \mathrm{l})$ \\
$\mathrm{fT}_{4}(0.7-1.5 \mathrm{ng} / \mathrm{dl})$ \\
$\mathrm{BMI}_{\text {at }}$ diagnosis $\left(\mathrm{kg} / \mathrm{m}^{2}\right)$
\end{tabular}

http://jme.endocrinology-journals.org DOI: 10.1530/JME-14-0083

\begin{tabular}{c}
\hline TPP \\
\hline $28.56 \pm 7.73(n: 36)$ \\
(range: $19-51$ years) \\
$2.25 \pm 0.55(n: 29)$ \\
$0.03 \pm 0.03(n: 36)$ \\
$5.29 \pm 2.84(n: 36)$ \\
$23.98 \pm 3.241(n: 17)$ \\
\hline
\end{tabular}

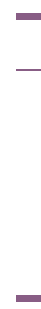

\begin{tabular}{r}
\hline $\boldsymbol{P}$ value \\
\hline$<0.001$ \\
$<0.001$ \\
0.433 \\
0.192 \\
0.936
\end{tabular}

C 2014 Society for Endocrinology Printed in Great Britain
Published by Bioscientifica Ltd. 
A

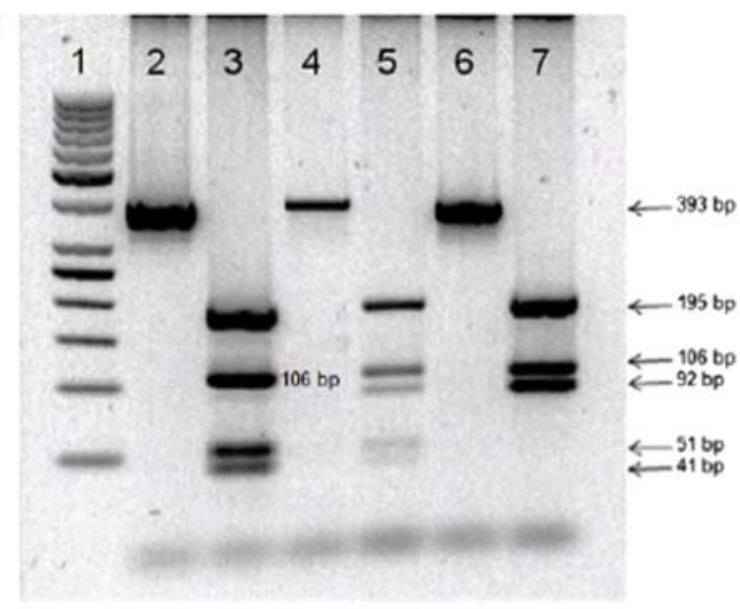

B

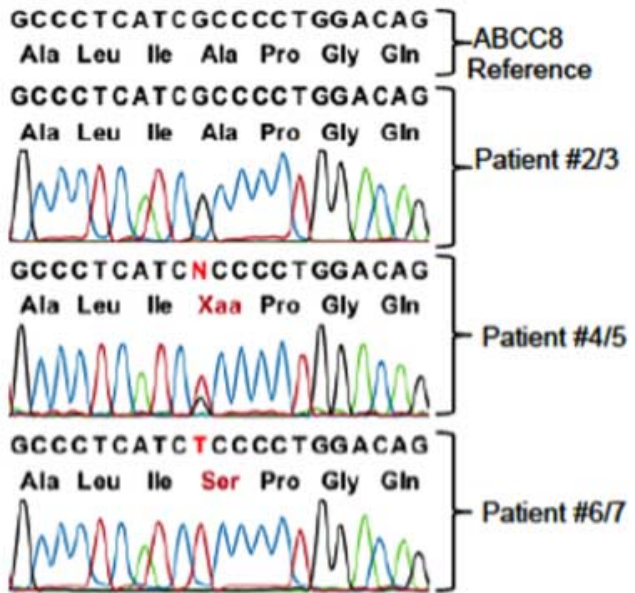

Figure 1

Sequencing and genotyping results of the p.Ala1369Ser variant (rs757110). (A) Representative electrophoresis of PCR products after restriction enzyme analysis using Mwol to screen the codon 1369 variant of the $A B C C 8$ (SUR1) gene. Lane 1: 100-bp DNA marker. Lanes 2, 4 and 6: non-digested amplified PCR product controls. Lane 3: a patient with a homozygous CC genotype (fragments of 195, 106, 51 and $41 \mathrm{bp}$ ). Lane 5: a patient with a heterozygous CA genotype (fragments of 195, 106, 92, 51 and $41 \mathrm{bp}$ ). Lane 6: a patient with a homozygous AA genotype (fragments of 195, 106 and $92 \mathrm{bp}$ ). (B) Representative electropherogram sequences of the SUR1 p.Ala1369Ser variant detected in patients corresponding to lanes 3, 5 and 7 . A full colour version of this figure is available via http://dx.doi.org/10.1530/ JME-14-0083.

TPP patients than in the TWP control subjects (61.1 vs $34.4 \%, \mathrm{OR}=3.42, P=0.039,95 \% \mathrm{CI}=1.03$ to 11.36 ). As for the allele frequency distributed in the specific ethnic groups, the relatively small number of cases per groups meant that there was insufficient statistical power for meaningful comparisons.

There was also a significant difference between TPP patients and the population genetics control data obtained from the 1000 Genomes database (Flicek et al. 2013) (61.1 vs $29.0 \%, \mathrm{OR}=4.87, P<0.005,95 \% \mathrm{CI}=1.83$ to 12.97). Furthermore, the C-allele frequencies were similar between the thyrotoxic control group and the population data (34.4 vs $29 \%$, $\mathrm{OR}=1.42, P=0.325,95 \%$ $\mathrm{CI}=0.70$ to 2.89). Thus, the $\mathrm{C}$-allele Ala1369 variant of the $A B C C 8$ gene is associated with TPP susceptibility.

\section{Discussion}

In this case-control study, we demonstrate for the first time, to our knowledge, that the frequency of the Ala1369 variant is significantly higher in TPP patients than in TWP patients, revealing an association between the insulinsensitivity-related p.Ala1369Ser genetic variant of SUR1 and TPP. SUR1 is the $\beta$ subunit of a KATP channel encoded by the $A B C C 8$ gene that is crucial for the maintenance of glucose homoeostasis (McTaggart et al. 2010). The closure of the KATP channel is a metabolic prerequisite for insulin secretion. KATP channels are large macromolecular complexes that form hetero-octamers, consisting of four inwardly rectifying potassium channel (Kir6.x) subunits that generate the pore surrounded by four regulatory SUR subunits (Inagaki et al. 1995). We focused on SUR1 because of the clinical observation of hyperinsulinaemia in TPP and, among all genes involved in the pathogenesis of hyperinsulinaemia, on the basis of published literature, $45 \%$ of mutations are found in ABCC 8 and KCNJ11 (KATP channels).

KATP channels demonstrate widespread tissue distribution and are abundant in skeletal muscles (Spruce et al. 1985, Ashcroft 1988). Kir6.2 represents the predominant Kir6.x isoform in skeletal muscle and is expressed with SUR2A to form the KATP metabolic channel complex. Moreover, Tricarico et al. (2006) demonstrated that SUR1, which is encoded by the $A B C C 8$ gene, is also expressed in skeletal muscle in a manner that is dependent on the muscle fibre type: fast-twitch muscles demonstrate significantly higher expression than slow-twitch muscles. Moreover, $A B C C 8$ is highly expressed in fast-twitch muscle fibre in which $\mathrm{T}_{3}$ has a seminal role (Tricarico et al. 2006, Marsili et al. 2010).

The ABCC 8 gene is composed of 39 exons and is located on chromosome 11p15.1. Several $A B C C 8$ variants have been described previously. In this study, we screened exon 33-37, where most mutations causing hyperinsulinaemia exist and focused on the most important SUR1 variant that confers insulin sensitivity, which is largely known as the non-synonymous variant p.Ala1369Ser (Hamming et al. 2009, Villareal et al. 2009).

Interestingly, the SUR1 p.Ala1369Ser variant appears to be in linkage disequilibrium (LD) with the p.Glu23Lys

Published by Bioscientifica Ltd 
Table 2 Genetic association analysis of the SUR1 p.Ala1369Ser variant observed in the TPP and control groups. The allele (C/A) and genotype (AA, CC, AC and CC or AC) for the p.Ala1369Ser (rs757110) in thyrotoxic periodic paralysis (TPP) patients, thyrotoxic without paralysis (TWP) control patients and the population genetics control (1000 Genomes Project/1KGP) are listed with frequencies, odds ratio (OR), $\mathrm{Cl}$ of $95 \%$ and $P$ value for comparisons when available. ORs and $\mathrm{Cls}$ were calculated using the non-risk genotype $(A C+A A)$ as a reference

\begin{tabular}{|c|c|c|c|c|c|c|c|c|c|}
\hline & $\begin{array}{c}\text { TPP } \\
(n=27)\end{array}$ & $\begin{array}{c}\text { TWP } \\
(n=32)\end{array}$ & OR & $95 \% \mathrm{Cl}$ & $P$ value $^{a}$ & $\begin{array}{c}\text { Population } \\
\text { genetics control } \\
(n=1092)\end{array}$ & OR & $95 \% \mathrm{Cl}$ & $P$ value $^{\mathrm{b}}$ \\
\hline \multicolumn{10}{|l|}{ Allele } \\
\hline A & 21 & 42 & & & & 1561 & & & \\
\hline $\mathrm{C}$ & 33 & 22 & 3.00 & 1.41 to 6.36 & 0.005 & 623 & 3.94 & 2.26 to 6.86 & $<0.0001$ \\
\hline \multicolumn{10}{|l|}{ Genotype } \\
\hline AA & 5 & 14 & 1.0 & & & 574 & & & \\
\hline $\mathrm{CC}$ & 11 & 4 & 7.69 & 1.66 to 35.70 & 0.014 & 105 & 12.03 & 4.16 to 50.0 & $<0.0001$ \\
\hline$A C$ & 11 & 14 & 2.20 & 0.61 to 8.00 & 0.344 & 413 & 3.057 & 1.05 to 8.86 & 0.040 \\
\hline$C C$ or $A C$ & 22 & 18 & 3.42 & 1.03 to 11.36 & 0.039 & 518 & 4.87 & 1.83 to 12.97 & $<0.05$ \\
\hline
\end{tabular}

variant in the neighbour KCNJ11 gene, which encodes the potassium channel Kir6.2 and is related to type 2 diabetes (T2D) susceptibility (Gloyn et al. 2003, Chistiakov et al. 2009). Thus, carriers of the alanine allele (Ala1369) of $A B C C 8$ may also carry the lysine (Lys23) variant of KCNJ11. We have also demonstrated previously that the variant Lys 23 was found in the majority among 22 TPP patients (Silva et al. 2004). A functional study provided evidence for an altered channel when these two variants are coexpressed (Lys23/Ala1369); this altered channel demonstrated an increased KATP channel activity in pancreatic $\beta$-cells (Hamming et al. 2009). These authors also demonstrated that the SUR1 p.Ala1369Ser variant may be responsible for T2D risk by decreasing the ATP sensitivity of the KATP channel (Hamming et al. 2009). Krugluger et al. (2000) verified that the Ala1369 variant is associated with an enhanced insulin response of the pancreatic $\beta$-cells after glucose intake in pregnant women, although this variant did not correlate with basal blood glucose levels.

KATP channels also modulate glucose uptake in skeletal muscle (McTaggart et al. 2010), in which they occur as hybrid assemblies of Kir6.2/SUR2A and Kir6.2/SUR1 subunits that are organised as homomeric complexes; SUR2B may also contribute to the functional channels (Tricarico et al. 2006). The mechanistic basis of muscle glucose metabolism in skeletal muscle remains poorly understood apart from its known insulin-enhancing glucose uptake. To illustrate this complexity, one study has reported enhanced peripheral insulin sensitivity in Lys23 (KK genotype) carriers using hyperinsulinaemic euglycaemic clamp, which revealed that hepatic insulin sensitivity is $\sim 40 \%$ greater in subjects with the Lys 23 variant, and these subjects demonstrate increased insulin sensitivity after oral glucose (Villareal et al. 2009). However, results from studies of null mice indicated that increased KATP channel activity would be expected to decrease insulin-dependent glucose uptake (Miki et al. 2002).

In our study, the frequency of the Ala1369 variant was significantly higher in TPP patients than in TWP patients and normal control populations, which reveals a new link between genetic susceptibility to TPP and the insulin response. The combination of hyperinsulinaemia and abnormally increased glucose-stimulated insulin secretion in TPP patients has been demonstrated in other studies (Chan et al. 1994, Soonthornpun et al. 2009). In fact, Soonthornpun and colleagues demonstrated that TPP patients exhibited lower insulin sensitivity. Using a euglycaemic hyperinsulinaemic clamp and a 75-g oral glucose tolerance test, these authors demonstrated that patients with TPP may be more resistant to insulin and, therefore, may be more likely to have hyperinsulinaemia (Soonthornpun et al. 2009). These authors also found that TPP patients exhibited a higher BMI and greater waist circumference than age/sex-matched controls who presented with TWP. Our results also indicated that the current BMI of patients with TPP was higher than that of patients with pure hyperthyroidism, confirming the results of Soonthornpun et al. (2009). Additionally, a Chinese study revealed that non-obese type 2 diabetic patients with the Ala1369 variant have a better hypoglycaemic response to anti-diabetic sulphonylurea drug gliclazide than Ser1369 patients, reinforcing the existence of insulinresponse genetic predisposition for those bearing this variant (Feng et al. 2008).

Published by Bioscientifica Ltd. 
In this study, the C-allele of the Ala1369 risk variant was present at a higher frequency in TPP patients than in the population genetics control that consisted of 1092 multi-ethnic subjects from the 1000 Genomes project. TPP is known to be more prevalent in Asian populations (Lin 2005). Interestingly, the TPP-risk C-allele is also more common in the Asian population than in the general population (41 vs 29\%) (Flicek et al. 2013). This finding may explain the prevalence of TPP susceptibility in Asians, followed in frequency by Brazilian patients; additional rs757110 frequency (risk C-allele SNP) investigations using other ethnic cohorts may provide additional evidence to support this idea.

Although we have found a statistical correlation between C-allele backgrounds and insulin sensitivity among TPP patients, published data regarding this SNP still remains very controversial. Data from two other T2D populations with different backgrounds did not reach the same genetic predisposition findings when assessing severe hypoglycaemia response to sulphonylurea treatment in German-Caucasians (Holstein et al. 2012) and Japanese (Sato et al. 2010) patients. Certainly, our cohort and these groups of T2D patients are metabolically different and were pharmacologically challenged. Besides, TPP patients are far from being hypoglycaemic despite their mild hyperinsulinaemic state. In fact, after being cured of thyrotoxic catabolic conditions, the latest measured BMI $\left(\mathrm{kg} / \mathrm{m}^{2}\right)$ in our TPP patients was $30.05 \pm$ 5.34 ( $n: 16)$ compared with $26.93 \pm 2.73(n: 29)$ observed in the TWP patients $(P<0.041)$.

During the genotyping and matching of our cohort of TPP and controls (TWP) for ABCC 8 variant, two Asian GWAS studies were published, indicating that a new TPP locus (17q24.3) has emerged (Cheung et al. 2012, Jongjaroenprasert et al. 2012). None of the genes related to insulin response is found within this locus, indicating that ABCC8 hyperinsulinaemia genetic predisposition is either an additional phenotype-modulating trait or an ethnic-dependent linked genetic association. The latter possibility might also be the explanation for the recent study by Chu et al. (2012), which demonstrated that TPP and non-thyrotoxic sporadic periodic paralysis shared the same susceptible genetic variant rs623011 on $17 \mathrm{q} 24.3$ independent of thyroid hormone.

Given the significant OR for its genetic susceptibility risk, it is conceivable that the SUR1 Ala1369 variant plays a role in insulin sensitivity, thus mediating the response to the carbohydrate-load triggering factor for thyrotoxic paralysis.
Declaration of interest

The authors declare that there is no conflict of interest that could be perceived as prejudicing the impartiality of the research reported.

\section{Funding}

This work was supported by São Paulo State Research Foundation-FAPESP grants 2006/60402-1 and 2010/51547-1 (to R M B M and M R D-S) and 2011/20747-8 (to M R D-S). A L R R is an MS student from the Brazilian Research Council (CNPq)

\section{Author contribution statement}

A L R R, R C M S M and M R D-S contributed to the study design. A L R R, R C M S M, R M B M and M R D-S contributed to sample cohort development. $A L R R, S C L$ and I S K contributed to experimental and analytical protocol development. ALRR, ISK and F C performed bench-top experiments. ALR R, I S K, F C, R C M S M and M R D-S performed data analysis. A L R R, S C L, R M B M and M R D-S performed manuscript preparation.

\section{Acknowledgements}

The authors thank the team of the LEMT, particularly Ângela Faria, Gilberto Furuzawa, Teresa Kasamatsu and the physicians Maria Izabel Chiamolera, Reinaldo Furlanetto, Luiza Matsumura, João R M Martins and Jairo Hidal.

\section{References}

Ashcroft FM 1988 Adenosine 5'-triphosphate-sensitive potassium channels. Annual Review of Neuroscience 11 97-118. (doi:10.1146/ annurev.ne.11.030188.000525)

Chan A, Shinde R, Chow CC, Cockram CS \& Swaminathan R 1991 In vivo and in vitro sodium pump activity in subjects with thyrotoxic periodic paralysis. BMJ 303 1096-1099. (doi:10.1136/bmj.303.6810.1096)

Chan A, Shinde R, Chow CC, Cockram CS \& Swaminathan R 1994 Hyperinsulinaemia and $\mathrm{Na}^{+}, \mathrm{K}^{+}$-ATPase activity in thyrotoxic periodic paralysis. Clinical Endocrinology 41 213-216. (doi:10.1111/ j.1365-2265.1994.tb02532.x)

Chang CC, Cheng CJ, Sung CC, Chiueh TS, Lee CH, Chau T \& Lin SH 2013 A 10-year analysis of thyrotoxic periodic paralysis in 135 patients: focus on symptomatology and precipitants. European Journal of Endocrinology 169 529-536. (doi:10.1530/EJE-13-0381)

Cheung CL, Lau KS, Ho AY, Lee KK, Tiu SC, Lau EY, Leung J, Tsang MW, Chan KW, Yeung CY et al. 2012 Genome-wide association study identifies a susceptibility locus for thyrotoxic periodic paralysis at 17q24.3. Nature Genetics 44 1026-1029. (doi:10.1038/ng.2367)

Chistiakov DA, Potapov VA, Khodirev DC, Shamkhalova MS, Shestakova MV \& Nosikov VV 2009 Genetic variations in the pancreatic ATP-sensitive potassium channel, $\beta$-cell dysfunction, and susceptibility to type 2 diabetes. Acta Diabetologica 46 43-49. (doi:10.1007/s00592-008-0056-5)

Chu PY, Cheng CJ, Tseng MH, Yang SS, Chen HC \& Lin SH 2012 Genetic variant rs623011 (17q24.3) associates with non-familial thyrotoxic and sporadic hypokalemic paralysis. Clinica Chimica Acta 414 105-108. (doi:10.1016/j.cca.2012.08.004)

Dias da Silva MR, Cerutti JM, Tengan CH, Furuzawa GK, Vieira TC, Gabbai AA \& Maciel RM 2002 Mutations linked to familial hypokalaemic periodic paralysis in the calcium channel $\alpha 1$ subunit gene $\left(\mathrm{Ca}_{\mathrm{v}} 1.1\right)$ are not associated with thyrotoxic hypokalaemic periodic paralysis. Clinical Endocrinology 56 367-375. (doi:10.1046) j.1365-2265.2002.01481.x)

Published by Bioscientifica Ltd. 
Feng Y, Mao G, Ren X, Xing H, Tang G, Li Q, Li X, Sun L, Yang J, Ma W et al. 2008 Ser1369Ala variant in sulfonylurea receptor gene $A B C C 8$ is associated with antidiabetic efficacy of gliclazide in Chinese type 2 diabetic patients. Diabetes Care 31 1939-1944. (doi:10.2337/dc072248)

Flicek P, Ahmed I, Amode MR, Barrell D, Beal K, Brent S, Carvalho-Silva D, Clapham P, Coates G, Fairley S et al. 2013 Ensembl 2013. Nucleic Acids Research 41 D48-D55. (doi:10.1093/nar/gks1236)

Gloyn AL, Weedon MN, Owen KR, Turner MJ, Knight BA, Hitman G, Walker M, Levy JC, Sampson M, Halford S et al. 2003 Large-scale association studies of variants in genes encoding the pancreatic $\beta$-cell $\mathrm{K}_{\mathrm{ATP}}$ channel subunits Kir6.2 (KCNJ11) and SUR1 (ABCC8) confirm that the KCNJ11 E23K variant is associated with type 2 diabetes. Diabetes 52 568-572. (doi:10.2337/diabetes.52.2.568)

Hamada N, Ishii T, Hasegawa M, Ishikawa N, Tabata T, Okuno Y, Ito K, Matsuura S, Morii H \& Wada M 1985 Transient glucose intolerance during attacks of thyrotoxic periodic paralysis. Hormone and Metabolic Research 17 301-305. (doi:10.1055/s-2007-1013524)

Hamming KS, Soliman D, Matemisz LC, Niazi O, Lang Y, Gloyn AL \& Light PE 2009 Coexpression of the type 2 diabetes susceptibility gene variants KCNJ11 E23K and ABCC8 S1369A alter the ATP and sulfonylurea sensitivities of the ATP-sensitive $\mathrm{K}^{+}$channel. Diabetes $\mathbf{5 8}$ 2419-2424. (doi:10.2337/db09-0143)

Holstein JD, Kovacs P, Patzer O, Stumvoll M \& Holstein A 2012 The Ser1369Ala variant of $A B C C 8$ and the risk for severe sulfonylureainduced hypoglycemia in German patients with type 2 diabetes. Pharmacogenomics 13 5-7 author reply 9-10. (doi:10.2217/pgs.11.150)

Inagaki N, Gonoi T, Clement JP IV, Namba N, Inazawa J, Gonzalez G, Aguilar-Bryan L, Seino S \& Bryan J 1995 Reconstitution of $I_{\mathrm{KATP}}$ : an inward rectifier subunit plus the sulfonylurea receptor. Science $\mathbf{2 7 0}$ 1166-1170. (doi:10.1126/science.270.5239.1166)

Jongjaroenprasert W, Phusantisampan T, Mahasirimongkol S, Mushiroda T, Hirankarn N, Snabboon T, Chanprasertyotin S, Tantiwong P, Soonthornpun S, Rattanapichart P et al. 2012 A genome-wide association study identifies novel susceptibility genetic variation for thyrotoxic hypokalemic periodic paralysis. Journal of Human Genetics $\mathbf{5 7}$ 301-304. (doi:10.1038/jhg.2012.20)

Krugluger W, Festa A, Shnawa N, Bucher J, Boltz-Nitulescu G, Schernthaner G \& Hopmeier P 2000 A serine/alanine polymorphism in the nucleotide-binding fold-2 of the sulphonylurea receptor-1 (S1369A) is associated with enhanced glucose-induced insulin secretion during pregnancy. Journal of Inherited Metabolic Disease 23 705-712. (doi:10.1023/A:1005630912875)

Kung AW 2006 Clinical review: thyrotoxic periodic paralysis: a diagnostic challenge. Journal of Clinical Endocrinology and Metabolism 91 2490-2495. (doi:10.1210/jc.2006-0356)

Lin SH 2005 Thyrotoxic periodic paralysis. Mayo Clinic Proceedings 80 99-105. (doi:10.1016/S0025-6196(11)62965-0)

Lin YF, Wu CC, Pei D, Chu SJ \& Lin SH 2003 Diagnosing thyrotoxic periodic paralysis in the ED. American Journal of Emergency Medicine 21 339-342. (doi:10.1016/S0735-6757(03)00037-8)

Maciel RM, Lindsey SC \& Dias da Silva MR 2011 Novel etiopathophysiological aspects of thyrotoxic periodic paralysis. Nature Reviews. Endocrinology 7 657-667. (doi:10.1038/nrendo.2011.58)

Marsili A, Ramadan W, Harney JW, Mulcahey M, Castroneves LA, Goemann IM, Wajner SM, Huang SA, Zavacki AM, Maia AL et al. 2010 Type 2 iodothyronine deiodinase levels are higher in slow-twitch than fast-twitch mouse skeletal muscle and are increased in hypothyroidism. Endocrinology 151 5952-5960. (doi:10.1210/en.2010-0631)

McFadzean AJ \& Yeung R 1967 Periodic paralysis complicating thyrotoxicosis in Chinese. BMJ 1 451-455. (doi:10.1136/bmj.1.5538.451)
McTaggart JS, Clark RH \& Ashcroft FM 2010 The role of the $\mathrm{K}_{\text {ATP }}$ channel in glucose homeostasis in health and disease: more than meets the islet. Journal of Physiology 588 3201-3209. (doi:10.1113/jphysiol.2010. 191767)

Miki T, Minami K, Zhang L, Morita M, Gonoi T, Shiuchi T, Minokoshi Y, Renaud JM \& Seino S 2002 ATP-sensitive potassium channels participate in glucose uptake in skeletal muscle and adipose tissue. American Journal of Physiology. Endocrinology and Metabolism 283 E1178-E1184. (doi:10.1152/ajpendo.00313.2002)

Ober KP 1992 Thyrotoxic periodic paralysis in the United States. Report of 7 cases and review of the literature. Medicine 71 109-120. (doi:10.1097/ 00005792-199205000-00001)

Okinaka S, Shizume K, Iino S, Watanabe A, Irie M, Noguchi A, Kuma S, Kuma K \& Ito T 1957 The association of periodic paralysis and hyperthyroidism in Japan. Journal of Clinical Endocrinology and Metabolism 17 1454-1459. (doi:10.1210/jcem-17-12-1454)

Rolim AL, Lindsey SC, Kunii IS, Fujikawa AM, Soares FA, Chiamolera MI, Maciel RM \& Silva MR 2010 Ion channelopathies in endocrinology: recent genetic findings and pathophysiological insights. Arquivos Brasileiros de Endocrinologia e Metabologia 54 673-681. (doi:10.1590/ S0004-27302010000800002)

Ryan DP, da Silva MR, Soong TW, Fontaine B, Donaldson MR, Kung AW, Jongjaroenprasert W, Liang MC, Khoo DH, Cheah JS et al. 2010 Mutations in potassium channel Kir2.6 cause susceptibility to thyrotoxic hypokalemic periodic paralysis. Cell 140 88-98. (doi:10.1016/j.cell.2009.12.024)

Sato R, Watanabe H, Genma R, Takeuchi M, Maekawa M \& Nakamura H 2010 ABCC8 polymorphism (Ser1369Ala): influence on severe hypoglycemia due to sulfonylureas. Pharmacogenomics 11 1743-1750. (doi:10.2217/pgs.10.135)

Shishiba Y, Shimizu T, Saito T \& Shizume K 1972 Elevated immunoreactive insulin concentration during spontaneous attacks in thyrotoxic periodic paralysis. Metabolism 21 285-290. (doi:10.1016/00260495(72)90071-6)

Silva MR, Chiamolera MI, Kasamatsu TS, Cerutti JM \& Maciel RM 2004 Thyrotoxic hypokalemic periodic paralysis, an endocrine emergency: clinical and genetic features in 25 patients. Arquivos Brasileiros de Endocrinologia e Metabologia 48 196-215. (doi:10.1590/ S0004-27302004000100022)

Soonthornpun S, Setasuban W \& Thamprasit A 2009 Insulin resistance in subjects with a history of thyrotoxic periodic paralysis (TPP). Clinical Endocrinology 70 794-797. (doi:10.1111/j.1365-2265.2008.03395.x)

Spruce AE, Standen NB \& Stanfield PR 1985 Voltage-dependent ATPsensitive potassium channels of skeletal muscle membrane. Nature $\mathbf{3 1 6}$ 736-738. (doi:10.1038/316736a0)

Tricarico D, Mele A, Lundquist AL, Desai RR, George AL Jr \& Conte Camerino D 2006 Hybrid assemblies of ATP-sensitive $\mathrm{K}^{+}$channels determine their muscle-type-dependent biophysical and pharmacological properties. PNAS 103 1118-1123. (doi:10.1073/pnas. 0505974103)

Villareal DT, Koster JC, Robertson H, Akrouh A, Miyake K, Bell GI, Patterson BW, Nichols CG \& Polonsky KS 2009 Kir6.2 variant E23K increases ATP-sensitive $\mathrm{K}^{+}$channel activity and is associated with impaired insulin release and enhanced insulin sensitivity in adults with normal glucose tolerance. Diabetes 58 1869-1878. (doi:10.2337/ db09-0025)

Vincze T, Posfai J \& Roberts RJ 2003 NEBcutter: a program to cleave DNA with restriction enzymes. Nucleic Acids Research 31 3688-3691. (doi:10.1093/nar/gkg526)

Received in final form 28 July 2014

Accepted 20 August 2014

Accepted Preprint published online 20 August 2014 http://jme.endocrinology-journals.org DOI: 10.1530/JME-14-0083
C 2014 Society for Endocrinology Printed in Great Britain 